\title{
Painless diabetic peripheral neuropathy: the forgotten complication
}

\section{Introduction}

Dr. Paul Brand was a renowned British physician and surgeon (1914-2003) whose work with patients with leprosy in India and the US revolutionized the treatment of patients with painless neuropathy from both leprosy and diabetes. In his book "The Gift of Pain," he explains that although suffering from pain can be agonizing, patients who cannot feel pain often have much worse outcomes such as foot ulcers and amputation.

\section{Painless DPN and the insensate foot}

Diabetic Peripheral Polyneuropathy (DPN) is a very common microvascular complication affecting millions of people with of both types of diabetes. About $2 / 3$ of patients with DPN have no symptoms, they are less likely to seek medical attention and many are totally unaware of their condition. Furthermore, many primary care physicians and even endocrinologists fail to examine their patient's feet to detect painless DPN. It is for this reason that we often consider diabetic neuropathy to be the "forgotten complication" of diabetes.

The American Diabetes Association recommends that all diabetic patients should be screened for diabetic peripheral neuropathy (DPN) starting at diagnosis of type 2 diabetes and 5years after the diagnosis of type 1 diabetes and at least annually thereafter, using simple clinical tests, such as a $10 \mathrm{~g}$ monofilament.

A focused neurologic examination of the lower extremities will detect sensory loss and confirm the classical distal symmetric polyneuropathy of diabetes. Loss of ankle jerks, reduced or absent touch or pinprick and loss of vibratory sensation are noted even in early cases. The insensate foot is defined as one with loss of protective sensation (LOPS), as demonstrated on exam by the inability to detect the 5.07(10gram) Semmes-Weinstein monofilament and/or the $128 \mathrm{~Hz}$ tuning fork. ${ }^{3}$ These patients may be asymptomatic or may note numbness, cold feet (from autonomic shunting of blood from the skin) and/or dry skin (from denervation of sweat glands. A concomitant motor neuropathy affects the flexor muscles. The loss of flexor strength allows the unopposed foot extensors to contract and pull the toes into a hammer or claw position. These deformities redistribute the weight onto the insensate metatarsal heads, greatly predisposing the neuropathic individual to ulceration.

\section{Foot ulceration and amputation}

Neuropathic foot ulcers are typically round ("punched out" appearance) and occur over a pressure point. As opposed to ischemic ulcers that are painful, neuropathic ulcers are painless. ${ }^{3}$ Patients may not be aware of these ulcers if they do not inspect their feet on a regular basis. The treatment consists of surgical debridement and deweighting the foot. If patients ignore the advice of their physician and walk on the ulcerated foot, it is just a matter of time before osteomyelitis occurs, particularly in the patients with poor glycemic control.

A causation study attributed $63 \%$ of foot ulcers to the critical triad of: 1) peripheral sensory neuropathy, 2) trauma and 3) deformities. ${ }^{4}$
Volume 3 Issue I - 2016

\author{
Robert Tanenberg \\ Department of Endocrinology, East Carolina University, USA
}

Correspondence: Robert Tanenberg, Department of Endocrinology, East Carolina University, USA, Tel 252744 2567, EmailTANENBERGR@ecu.edu

Received: January 25, 2016 | Published: February 26, 2016

Foot ulceration often leads to amputation which can have a significant impact on both quality of and life expectancy in the patient with diabetes. In 2010, about 73,000 non-traumatic lower-limb amputations were performed in adults aged 20years or older with diagnosed diabetes and about $60 \%$ of non-traumatic lower-limb amputations among people aged 20years or older occur in people with diagnosed diabetes. ${ }^{5}$

In a classic study, patients with diabetes in a well-defined American-Indian population were stratified into four risk groups based on sensation status to the 5.07 monofilament, the presence of foot deformity, and a history of lower-extremity events (amputation or ulceration). The group definitions (and distribution percentages) were: Category 0 , sensate $(74.3 \%)$; Category 1 , insensate $(8.4 \%)$; Category 2 , insensate with deformity (4.5\%); and Category 3 , history of lower extremity event $(13 \%)$. These cohorts were followed prospectively for lower extremity events and changes in sensation status. Over a 32-mo follow-up period, 41 patients developed ulcerations, and incidence rates correlated positively with increasing risk category (P less than 0.00001). All 14 amputations occurred in risk groups 2 and $3 .^{6}$ It should be recognized that patients with insensate feet may paradoxically have severe lower extremity pain which occurs from small fibers that cannot be confirmed on neurologic examination or standard electrophysiologic testing.

\section{Ulcer prevention}

The International Consensus of the Diabetic Foot has identified 5 key elements as cornerstones of foot management for the patient with diabetes.

These include:

i. Regular inspection and examination of the foot

ii. Identification of the foot at risk

iii. Education of the patient, their family, and providers

iv. Appropriate footwear

v. Treatment of non-ulcerative pathology

Custom or modified footwear is critical in preventing ulceration in patients with insensate feet, deformities, or a past history of a foot ulcer. Referral to a certified pedorthist to create custom shoes or insoles is highly recommended. 


\section{Conclusion}

DPN may present clinically as painful or painless. In both cases, early and aggressive control of glucose, blood pressure and lipids are essential to improve the disorder. Early diagnosis of sensory loss in the lower extremities is critical to prevent progression to a totally insensate foot. High risk feet can be treated with custom footwear to prevent neuropathic ulceration and amputation. Diabetic neuropathy is a complication that should never be forgotten.

\section{Acknowledgements}

None.

\section{Conflict of interest}

Author declares that there is no conflict of interest.

\section{References}

1. Brand PW, Yancy P. The Gift of Pain. Zondervan, Grand Rapids, MI, USA; 1997.
2. Tanenberg R, Pfeifer M. Neuropathy: The Forgotten Complication. Diabetes Forecast. 2000;12:56-60.

3. Tanenberg RJ, Donofrio PD. Neuropathic Problems of the Lower Extremities in Diabetic Patients. In: Levin, O'Neal's. The Diabetic Foot 7th ed. In: Pfeifer MA, Bowker J, editors. Philadelphia, PA: Mosby Elsevier; 2008;33-74.

4. Rieber GE, Boyko EJ, Del Aguila M, et al. Causal Pathways for Incident Lower-Extremity Ulcers in Patients with Diabetes from Two Settings. Diabetes Care. 1999;22(1):157-162.

5. CDC. National Diabetes Statistics Report. Centers for Disease Controls \& Preventions. 2014

6. Rith-Najarian SJ, Stolusky T, Gohdes DM. Identifying diabetic patients at high risk for lower-extremity amputation in a primary health care setting. A prospective evaluation of simple screening criteria. Diabetes Care. 1992;15(10):1386-1389.

7. Apelqvist J, Bakker K, van Houtum WH, et al. Practical guidelines on the management and prevention of the diabetic foot. International Working Group on the Diabetic Foot (IWGDF) Editorial Board. Diabetes Metab Res Rev. 2008;24(Suppl 1):S181-S187. 